\title{
PENGARUH JOB INVOLVEMENT DAN JOB SATISFACTION TERHADAP ORGANIZATIONAL CITIZENSHIP BEHAVIOUR SERTA DAMPAKNYA PADA KNOWLEDGE SHARING DI PT INDOLIFT SUKSES ABADI
}

\author{
Tinjung Desy Nursanti; Ebenhaezer Samudera; Fajar Widiansyah \\ School of Business Management, BINUS University \\ Jln. K.H. Syahdan No.9, Palmerah, Jakarta Barat 11480 \\ tinjungdesy@yahoo.com; ebenhaezerlee@gmail.com; fajar.widiansyah@gmail.com
}

\begin{abstract}
The research was conducted at PT Indolift Sukses Abadi, a folklift distributor that sells and distributes all heavy equipment products. The objective of this study was to determine whether there is any influence of job involvement and job satisfaction on organizational citizenship behavior that impact to knowledge sharing. Data were obtained by distributing a questionnaire to 100 respondents of the company; and then were processed using Path Analysis Technique. Based on this research, job involvement and job satisfaction partially and simultaneously have influence on organizational citizenship behaviour. Then, job satisfaction and organizational citizenship behaviour partially have influence on knowledge sharing. However, job involvement partially has no influence on knowledge sharing. Nevertheless, job involvement, job satisfaction, and organizational citizenship behavior simultaneously have influence on knowledge sharing.
\end{abstract}

Keywords: job involvement, job satisfaction, organizational citizenship behaviour, knowledge sharing

\begin{abstract}
ABSTRAK
Penelitian dilakukan di PT Indolift Sukses Abadi, yang merupakan distributor folklift yang menjual dan menyalurkan berbagai macam alat berat. Tujuan dari penelitian ini adalah untuk mengetahui apakah terdapat pengaruh dari job involvement dan job satisfaction terhadap organizational citizenship behavior serta dampaknya kepada knowledge sharing. Sampel penelitian ini sejumlah 100 orang karyawan PT Indolift Sukses Abadi. Pengumpulan data dilakukan dengan menggunakan kuesioner kemudian diolah dengan menggunakan teknik path analysis. Berdasarkan hasil penelitian, job involvement dan job satisfaction memiliki pengaruh secara parsial maupun simultan terhadap organizational citizenship behaviour. Kemudian job satisfaction dan organizational citizenship behaviour mempunyai pengaruh secara parsial terhadap knowledge sharing. Akan tetapi, job involvement tidak mempunyai pengaruh secara parsial terhadap knowledge sharing. Walau demikian, job involvement, job satisfaction, dan organizational citizenship behaviour mempunyai pengaruh secara simultan terhadap knowledge sharing.
\end{abstract}

Kata kunci: job involvement, job satisfaction, organizational citizenship behaviour, knowledge sharing 


\section{PENDAHULUAN}

Seiring dengan makin pesatnya pembangunan di bidang infrastruktur, perkembangan industri alat berat di Indonesia juga ikut mengalami pertumbuhan secara signifikan, terutama dalam kurun waktu enam tahun terkahir. Bahkan untuk wilayah Asia Tenggara, Indonesia adalah negara yang memiliki industri alat berat terlengkap dan maju. Hampir setiap tahunnya volume penjualan alat-alat berat cenderung meningkat. PT Indolift Sukses Abadi pada awalnya merupakan perusahaan spesialisasi pembuat forklift part yang didirikan sejak 1993. Saat ini perusahaan mengalami perkembangan tidak hanya menjadi produsen, tetapi juga telah berkembang menjadi importir forklift parts yang melayani distribusi penjualan skala besar dan kecil (wholeseller and retailer).

Kemajuan prestasi seperti ini sudah pasti dekat dengan persaingan. Terlebih lagi, perusahaan berada di ibukota Jakarta yang terdapat banyak perusahaan kecil atau besar, baik yang berasal dari dalam negeri maupun dari luar negeri. Dari hasil wawancara yang dilakukan dengan bapak Fong Sumarsono selaku General Manager PT Indolift Sukses Abadi, disimpulkan bahwa knowledge sharing merupakan masalah utama pada PT Indolift Sukses Abadi karena PT Indolift Sukses Abadi memberlakukan sistem bonus kepada karyawannya yang bisa mencapai target. Oleh karena itu, karyawan menganggap bahwa rekan kerja adalah pesaing dan hal ini menjadikan mereka enggan untuk berbagi pengetahuan yang mereka miliki.

Knowledge sharing merupakan proses komunikasi informal yang melibatkan sesama karyawan (Siemsen, Roth, \& Balasubramanian, 2008). Setiap karyawan di suatu perusahaan akan lebih baik jika memiliki skill dan knowledge ketika mereka terlibat dalam knowledge sharing. Para atasan perusahaan pun biasanya menghargai kegiatan knowledge sharing ini karena knowledge sharing antarkaryawan akan membuat pekerjaan individu lebih mudah, dan juga menghemat waktu setiap karyawan untuk mengerjakan tugas-tugas yang lain. Meskipun demikian, sulit untuk menjalankan praktik knowledge sharing karena faktor karyawannya sendiri. Hampir di setiap tempat kerja knowledge sharing sudah menjadi masalah yang relatif umum karena setiap karyawan secara individu yang mempunyai pengetahuan lebih jarang untuk saling berbagi pengetahuan mereka (Ho, Hsu, \& Oh, 2009). Knowledge sharing tidak akan terjadi jika salah satu dari karyawan tidak berniat untuk saling berbagi terhadap yang karyawan lainnya (Siemsen, Roth, \& Balasubramanian, 2008).

Faktor-faktor lain yang memengaruhi knowledge sharing adalah job satisfaction dan job involvement. Meningkatkan job involvement dapat meningkatkan kinerja perusahaan dengan cara mengarahkan karyawannya untuk lebih fokus terhadap pekerjaan mereka dan membuat pekerjaan menjadi pengalaman yang baru (Brown, 1996). Probst, Steffen, dan Romhardt (2000) menyatakan bahwa job involvement akan membuat karyawan merasa lebih percaya diri dan siap untuk melakukan knowledge sharing tentang pekerjaan dan pengalaman mereka dibanding dengan karyawan yang memiliki job involvement rendah. Adapun Organ (1977) menjelaskan mengenai logika job satisfaction, bahwa kinerja dianggap sebagai bentuk yang tepat dari balasan bagi perusahaan demi mendapatkan pengalaman job satisfaction oleh karyawan. Karyawan dengan job satisfaction yang tinggi akan menyebabkan pembentukan organizational citizenship behavior (OCB), sehingga muncul perasaan sukarela untuk berbagi pengetahuan dengan karyawan lain (Bateman \& Organ, 1983).

Daft (2010) menyatakan bahwa OCB adalah perilaku kerja yang melebihi persyaratan kerja dan turut berperan dalam kesuksesan organisasi. Seorang karyawan mendemonstrasikan OCB dengan cara membantu rekan sekerja dan pelanggan, melakukan kerja ekstra jika dibutuhkan, dan mencari jalan untuk memperbaiki produk dan prosedur. Teh dan Sun (2012) menunjukkan bahwa karyawan termotivasi untuk berbagi pengetahuan dengan yang lain saat mereka merasakan tingkat keterlibatan kerja (job involvement) yang tinggi dan mendapatkan kepuasan kerja (job satisfafction) yang sesuai. Organisasi harus meningkatkan lagi tingkat keterlibatan kerja setiap karyawan dan memberikan penghargaan yang lebih pantas diterima oleh mereka. Penelitian Al-Zu’bi (2011) menghasilkan 
simpulan bahwa seluruh dimensi dari organizational citizenship behaviour memiliki dampak yang positif kepada knowledge sharing. Dimensi-dimensi yang dimaksudkan adalah altruism, conscientiousness, sportsmanship, courtssy, civic virtue. Berdasarkan hasil tersebut, tingkat kontribusi kerja yang melebihi deskripsi kerja formal yang dilakukan secara sukarela dapat memengaruhi knowledge sharing pada sebuah organisasi.

Perusahaan yang berkembang, tidak hanya memerhatikan keuntungan yang dicapai perusahaan saja tetapi juga kesejahteraan dan kualitas SDM yang ada dalam perusahaan tersebut. Berdasarkan uraian, penelitian dilakukan untuk mengetahui apakah terdapat pengaruh job involvement dan job satisfaction terhadap organizational citizenship behaviour serta dampaknya pada knowledge sharing di PT Indolift Sukses Abadi. Pertanyaan-pertanyaan yang muncul dan akan dijawab dalam penelitian ini adalah: (1) apakah job involvement dan job satisfaction dapat berkontribusi secara signifikan terhadap organizational citizenship behavior; (2) apakah job involvement, job satisfaction, dan organizational citizenship behavior dapat berpengaruh secara signifikan terhadap knowledge sharing.

Tujuan dari penelitian ini adalah untuk mengetahui ada tidaknya pengaruh yang signifikan dari job involvement dan job satisfaction terhadap organizational citizenship behaviour serta dampaknya pada knowledge sharing di PT Indolift Sukses Abadi. Berdasarkan rumusan masalah diharapkan perusahaan akan mengetahui hal-hal berikut. Pertama, informasi mengenai pengaruh job involvement dan job satisfaction pada karyawan PT Indolift Sukses Abadi terhadap organizational citizenship behavior. Kedua, informasi mengenai pengaruh job involvement, job satisfaction dan organizational citizenship behaviour yang dirasakan oleh karyawan PT Indolift Sukses Abadi terhadap knowledge sharing yang dilakukan oleh antarrekan kerja.

\section{METODE}

Penelitian ini menggunakan metode survei, yaitu penelitian yang digunakan untuk mendapatkan data dari tempat tertentu yang alamiah (bukan buatan), tetapi peneliti melakukan perlakuan pengumpulan data, misalnya dengan mengedarkan kuesioner, tes, wawancara terstruktur, dan sebagainya (Sugiyono, 2009). Sedangkan jenis penelitian yang digunakan adalah penelitian deskriptif-asosiatif. Penelitian deskriptif-asosiatif merupakan penelitian yang menggunakan karakteristik variabel yang sudah diteliti sebelumnya dan tujuan penelitian ini juga untuk mengetahui pengaruh antara dua variabel atau lebih.

Dalam hal ini, penelitian fokus pada pengaruh antara job involvement dan job satisfaction terhadap organizational citizenship behaviour serta dampaknya kepada knowledge sharing sebagai permasalahan yang ada pada PT Indolift Sukses Abadi. Dalam penelitian ini, proses pengumpulan data dilakukan melalui penyebaran kuesioner kepada para responden, yaitu karyawan PT Indolift Sukses Abadi. Dengan demikian, unit analisis dalam penelitian ini adalah individu. Kemudian data yang berasal dari kuesioner tersebut diolah menggunakan SPSS versi 18 dan dianalisis untuk selanjutnya dijelaskan dengan bahasa yang mudah dipahami.

Time horizon dalam penelitian ini bersifat cross sectional. Informasi yang dikumpulkan hanya sekali dengan tujuan untuk mendapatkan jawaban atas pertanyaan penelitian (Sekaran \& Bougie, 2010). Adapun jenis data yang digunakan dalam penelitian ini adalah data kuantitatif. Data penelitian berupa angka-angka dan analisis menggunakan statistik (Sugiyono, 2009).

Sumber data primer diperoleh dengan cara menyebarkan suatu daftar pernyataan (kuesioner) yang cukup terinci dan lengkap tentang objek yang diteliti kepada karyawan PT Indolift Sukses Abadi. Metode ini digunakan untuk mengukur pengaruh job involvement dan job satisfaction terhadap organizational citizenship behaviour serta dampaknya kepada knowledge sharing setiap karyawan 
melalui pemberian bobot pada setiap jawaban. Data sekunder diperoleh berdasarkan penelitian terdahulu yang dilakukan oleh peneliti sebelumnya. Data diperoleh dari pustaka yang menunjang serta literatur yang ada.

Teknik pengumpulan data yang dilakukan dalam penelitian ini adalah melalui penyebaran kuesioner dengan memberikan seperangkat pertanyaan atau pernyataan tertulis kepada responden untuk dijawab (Sugiyono, 2009). Responden pada penelitian ini adalah seluruh karyawan yang ada di PT Indolift Sukses Abadi. Pengambilan sampel dilakukan dengan cara metode sensus, yaitu dengan mengambil seluruh karyawan PT Indolift Sukses Abadi sebanyak 100 orang. Pengolahan data dilakukan dengan bantuan komputer dengan program SPSS (Statistical Product and Service Solution).

Analisis diawali dengan pengumpulan dan pengolahan data yang diperoleh dari kuesioner dengan menggunakan skala Likert. Kemudian, skala diubah dari ordinal menjadi interval lalu dilakukan uji validitas dan reliabilitas serta uji normalitas. Hasil olahan data tersebut dianalisis lebih lanjut untuk menjawab tujuan penelitian dengan menggunakan analisis jalur (path analysis).

Berdasarkan wawancara dengan General Manager PT Indolift Sukses Abadi, diketahui bahwa tujuan yang ingin dicapai perusahaan dalam hal internal perusahaan adalah untuk memaksimalkan kualitas dan knowledge setiap karyawan yang ada di PT Indolift Sukses Abadi. Dari data yang diperoleh dari penyebaran kuesioner, para karyawan PT Indolift Sukses Abadi merasa bahwa lingkungan kerja adalah sebuah arena persaingan karyawan. Hal itu disebabkan oleh sistem bonus yang diberlakukan PT Indolift Sukses Abadi dalam perusahaan. Tujuan penelitian diharapkan dapat memberikan informasi kepada perusahaan mengenai variabel-variabel yang memengaruhi terciptanya knowledge sharing pada karyawan PT Indolift Sukses Abadi.

\section{HASIL DAN PEMBAHASAN}

Dari 100 orang karyawan yang dijadikan responden penelitian, seluruh karakteristik berdasarkan usia, jenis kelamin, posisi pekerjaan, lama bekerja, kisaran gaji, diketahui sebagai berikut. Jumlah karyawan laki-laki jauh lebih besar daripada jumlah karyawan perempuan (81 orang laki-laki, sisanya 10 orang perempuan). Hal ini dimungkinkan dengan lingkungan kerja yang memang lebih didominasi oleh jenis usaha yang dihasilkan. Kemudian, secara umum karyawan produktif di perusahaan berusia $36-40$ tahun sebanyak 20 orang. Adapun sebanyak 63 orang karyawan bekerja di bagian operasional karena perusahaan ini pada dasarnya adalah perusahaan manufaktur, dengan kisaran gaji bulanan yang diterima antara 2 juta -5 juta rupiah. Ditinjau dari lama bekerja di perusahaan, sebanyak 45 orang telah bekerja lebih dari 5 tahun di perusahaan. Dengan demikian, dapat dikatakan bahwa perusahaan berupaya memberikan perhatian yang besar bagi karyawannya agar tetap loyal bekerja di perusahaan.

Tahapan yang dilalui dalam proses pengujian dan analisis data dimulai dari mentransformasikan data ordinal menjadi data interval dengan menggunakan Methods of Successive Interval (MSI). Tujuannya adalah untuk mengetahui nilai alternatif masing-masing butir pertanyaan pada setiap variabel penelitian. Kemudian, dilanjutkan dengan uji validitas dan reliabilitas untuk mengetahui valid tidaknya butir-butir pertanyaan yang diajukan kepada responden dan apakah penelitian ini reliabel. Uji validitas menggunakan tingkat kepercayaan $95 \%$, dengan $\mathrm{df}=\mathrm{n}-2$. Nilai $\mathrm{n}$ dalam penelitian ini yaitu 100 orang, sehingga nilai $\mathrm{df}=98$. Selanjutnya dengan menggunakan rumus $r_{\text {tabel}}$, maka diperoleh nilai $r_{\text {tabel }}=0,17$.

Dasar pengambilan keputusan pada uji validitas ini adalah sebagai berikut. Jika $r_{\text {hitung }} \geq 0,17$, butir pertanyaan tersebut valid; jika $\mathrm{r}_{\text {hitung }}<0,17$, butir pertanyaan tersebut tidak valid. Sedangkan dasar pengambilan keputusan pada uji reliabilitas adalah sebagai berikut. Jika Cronbach Alpha $\geq 0,17$, 
data reliabel; jika Cronbach Alpha $<0,17$, data tidak reliabel. Untuk menguji reliabilitas data dapat dilakukan melalui SPSS, dengan hasil perhitungan apabila diperoleh nilai Cronbach Alpha $=0,886>$ $0,17\left(\mathrm{r}_{\text {tabel }}\right)$, data dikatakan reliabel. Hasil pengujian seluruh variabel penelitian ini menunjukkan bahwa nilai Cronbach Alpha lebih besar dari 0,17 sehingga analisis data penelitian ini dapat dilanjutkan. Demikian pula dengan hasil uji validitas masing-masing variabel juga menunjukkan nilai yang valid.

Selanjutnya uji normalitas data dilakukan untuk mengetahui apakah data berdistribusi normal. Uji normalitas dilakukan terhadap rata-rata dari nilai butir-butir yang dinyatakan valid dan reliabel melalui bantuan SPSS dengan menggunakan uji Kolmogorov-Smirnov serta uji Shapiro-Wilk. Apabila nilai sig lebih besar dari 0,05, dapat dikatakan data berdistribusi normal. Dari seluruh hasil pengujian terhadap masing-masing variabel, dinyatakan bahwa seluruh data variabel dinyatakan berdistribusi normal sehingga memenuhi asumsi untuk digunakan dalam analisis jalur (path analysis).

\section{Sub-struktur 1}

Tabel 1 Kontribusi Variabel Job Involvement dan Job Satisfaction terhadap Organizational Citizenship Behaviour

\begin{tabular}{lcccr}
\hline Model & $R$ & $R$ Square & Adjusted R Square & $\begin{array}{c}\text { Std. Error of the } \\
\text { Estimate }\end{array}$ \\
\hline 1 & .876 & .873 & .22070 \\
\hline a. Predictors: (Constant), Job Satisfaction,Job Involvement & \\
b. Dependent Variable: Organizational Citizenship Behaviour
\end{tabular}

Sumber: Data kuesioner yang telah diolah (2014)

Nilai R menunjukkan bahwa nilai hubungan antara job involvement (X1) dan job satisfaction (X2) terhadap organizational citizenship behavior (Y) mempunyai hubungan positif sebesar 0,936 termasuk dalam kategori sangat kuat. R Square pada Tabel 1 sebesar 0,876 berarti besar nilai Organizational Citizenship Behaviour (Y) dipengaruhi oleh Job Involvement (X1) dan Job Satisfaction (X2) sebesar 87,6\% dan sisanya sebesar 12,4\% dipengaruhi oleh variabel - variabel lain yang berada di luar penelitian ini.

\section{Sub-struktur 2}

Tabel 2 Hubungan Koefisien Korelasi Variabel Job Involvement dan Job Satisfaction dan Organizational Citizenship Behaviour terhadap Knowledge Sharing

\begin{tabular}{|c|c|c|c|c|c|c|}
\hline \multirow[b]{2}{*}{ Model } & & \multicolumn{2}{|c|}{ Unstandardized Coefficients } & \multirow{2}{*}{$\begin{array}{c}\text { Standardized } \\
\text { Coefficients }\end{array}$} & \multirow[b]{2}{*}{$t$} & \multirow[b]{2}{*}{ Sig. } \\
\hline & & $B$ & Std. Error & & & \\
\hline \multirow[t]{4}{*}{1} & (Constant) & .478 & .128 & & 3.743 & .000 \\
\hline & job involvement & -.017 & .042 & -.017 & -.403 & .688 \\
\hline & job satisfaction & -.252 & .086 & -.282 & -2.933 & .004 \\
\hline & $\begin{array}{l}\text { Organizational } \\
\text { citizenship } \\
\text { behaviour }\end{array}$ & 1.158 & .098 & 1.200 & 11.861 & .000 \\
\hline
\end{tabular}

a. Dependent Variable: knowledge sharing

Sumber: Data kuesioner yang telah diolah (2014) 
Dari hasil tabel koefisien jalur sub-struktur 2 (Tabel 2) diketahui bahwa hubungan job involvement terhadap knowledge sharing pada kolom nilai Sig sebesar 0,688. Berdasarkan dasar pengambilan keputusan (dengan tingkat kepercayaan 95\%) dapat disimpulkan bahwa 0,688 $>0,05$. Dapat dijelaskan, variabel job involvement (X1) tidak berkontribusi secara signifikan terhadap variabel knowledge sharing (Z). Karena ada variabel yang tidak berkontribusi, langkah model sub-struktur 2 perlu diperbaiki dengan melakukan metode Trimming. Metode Trimming dilakukan dengan mengeluarkan variabel job involvement (X1) dengan hasil dari koefisien jalur tidak signifikan dari analisis. Lalu, pengujian akan diulang namun variabel job involvement (X1) tidak diikutsertakan.

\section{Trimming}

Tabel 3 Kontribusi Variabel Job Involvement dan Job Satisfaction dan Organizational Citizenship Behaviour terhadap Knowledge Sharing

\begin{tabular}{|c|c|c|c|c|}
\hline Model & $R$ & $R$ Square & Adjusted R Square & $\begin{array}{l}\text { Std. Error of the } \\
\text { Estimate }\end{array}$ \\
\hline 1 & $.937^{\mathrm{a}}$ & .877 & .875 & .21133 \\
\hline
\end{tabular}

Sumber: Data kuesioner yang telah diolah (2014)

Nilai $\mathrm{R}$ menunjukkan bahwa antara job involvement (X1), job satisfaction (X2) dan organizational citizenship behaviour (Y) terhadap knowledge sharing (Z) mempunyai hubungan positif dengan nilai sebesar 0,937 termasuk dalam kategori sangat kuat. R Square pada Tabel 3 sebesar 0,877 berarti besar nilai knowledge sharing (Z) dipengaruhi oleh job involvement (X1) dan job satisfaction (X2) serta organizational citizenship behaviour (Y) sebesar 87,7\% dan sisanya sebesar $12,3 \%$ dipengaruhi oleh variabel-variabel lain yang berada di luar penelitian ini. Hasil analisis dapat dilihat dalam bagan sebagai berikut.

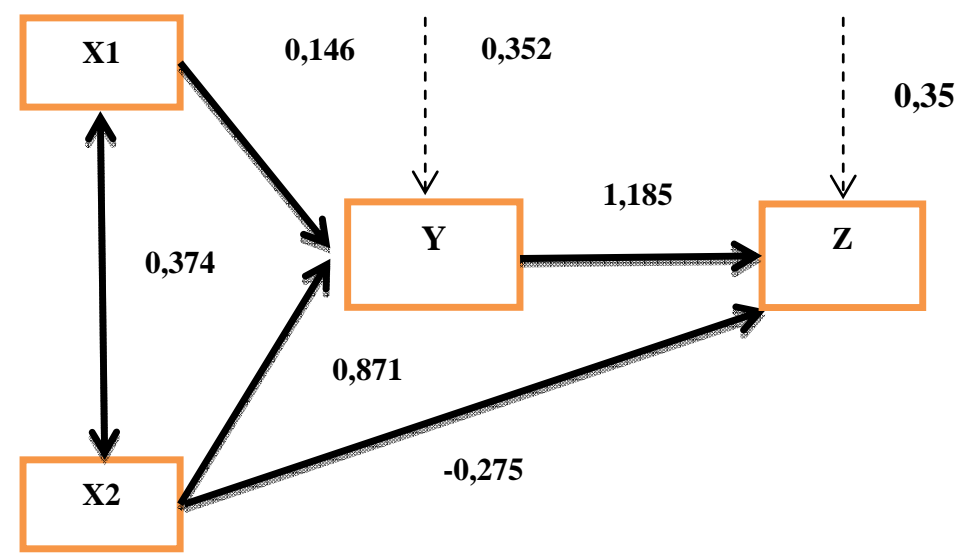

Gambar 1 Bagan Hasil Penelitian 


\section{SIMPULAN}

Berdasarkan hasil penelitian ini, dapat ditarik simpulan sebagai berikut. Pertama, variabel job involvement dan job satisfaction berpengaruh secara signifikan baik secara parsial maupun simultan terhadap variabel organizational citizenship behaviour. Kedua, variabel job involvement, job satisfaction, dan organizational citizenship behaviour berpengaruh secara signifikan secara simultan. Apabila secara parsial, job involvement tidak berpengaruh secara langsung terhadap knowledge sharing. Sedangkan job satisfaction dan organizational citizenship behaviour berpengaruh secara langsung terhadap knowledge sharing.

\section{Saran}

Berdasarkan hasil analisis dan pembahasan, maka beberapa hal dapat dilakukan PT Indolift Sukses Abadi sehubungan dengan usaha untuk meningkatkan knowledge sharing pada karyawannya dan juga bagi para peneliti yang akan melakukan kegiatan penelitian selanjutnya. Bagi PT Indolift Sukses Abadi, job involvement menjadi salah satu perhatian utama PT Indolift Sukses Abadi. Rendahnya job involvement pada karyawan perusahaan akan menyebabkan knowledge sharing sulit ditanamkan dalam benak setiap karyawan. Job involvement dapat dilakukan dengan cara mengajak para karyawan untuk ikut terlibat dalam proyek-proyek yang sedang dikerjakan oleh perusahaan, sebagai contoh dengan menampung ide-ide atau inovasi yang dikeluarkan oleh para karyawan dan bersama-sama mendiskusikan pilihan-pilihan yang ada dan dianggap baik untuk perusahaan.

PT Indolift Sukses Abadi dapat melakukan perbaikan dalam hubungan internal perusahaan yang lebih diprioritaskan pada hubungan antara atasan dengan bawahan untuk menghindari permasalahan intrapersonal di dalam perusahaan. Ada baiknya PT Indolift Sukses Abadi memercayakan karyawannya untuk mengerjakan pekerjaan yang lebih menantang dan memberikan ganjaran atau upah yang sesuai dengan hasil dari pekerjaan mereka, sehingga akan tercipta perasaan dicapainya kepuasan kerja (job satisfaction) dalam diri para karyawan karena telah dapat menyelesaikan pekerjaan yang dipercayakan kepada mereka.

PT Indolift Sukses Abadi sebaiknya tidak memberlakukan sistem pembagian bonus dengan target kepada karyawannya. Hal itu disebabkan dengan sistem pembagian bonus, karyawan yang telah puas dengan pekerjaannya dan menerima bonus akan lebih segan berbagi pengetahuan dengan karyawan lain karena rasa takut jika hasil yang mereka terima tersaingi atau jatuh pada karyawan lain. Perusahaan dapat lebih mendekatkan hubungan antarkaryawan untuk membangun kepercayaan terhadap sesama karyawan karena tanpa adanya rasa saling percaya antarkaryawan, mereka tidak akan mau untuk berbagi pengetahuannya.

Para peneliti selanjutnya dapat meneliti lebih lanjut mengenai faktor-faktor lainnya yang dapat mendorong terciptanya knowledge sharing pada PT Indolift Sukses Abadi atau perusahaan lainnya. Peneliti selanjutnya dapat melakukan penelitian di PT Indolift Sukses Abadi atau pada perusahaan lain agar dapat mengetahui apakah faktor lain yang dapat membuat karyawan melakukan knowledge sharing adalah faktor yang sama atau berbeda sehingga PT Indolift Sukses Abadi atau perusahaan lainnya dapat menetapkan faktor-faktor seperti apa yang sesuai di dalam lingkungan perusahaan. 


\section{DAFTAR PUSTAKA}

Al-Zu'bi, H. A. (2011). Organizational citizenship behaviour and impacts on knowledge sharing. International Business Research, 4(3), 221-227.

Bateman, T. S., \& Organ, D. W. (1983). Job satisfaction and the good soldier: The relationship between affect and employee citizenship. Academy of Management Journal, 26(4), 587-595.

Brown, S. P. (1996). A meta-analysis and review of organizational research on job involvement. Psychological Bulletin, 120(2), 235-255.

Daft, R. L. (2010). Organization Theory and Design (10 ed). USA: Cengage Learning.

Ho, C. T. B., Hsu, S. F., \& Oh, K. B. (2009). Knowledge sharing: Game and reasoned action perspectives. Industrial Management \& Data Systems, 109(9), 1211-1230.

Organ, D. W. (1977). A reappraisal and reinterpretation of the satisfaction-causes-performance hypothesis. Academy of Management Review, 2(1), 46-53.

Probst, G. J. B., Steffen, R., \& Romhardt, K. (2000). Managing Knowledge: Building blocks for success. Chichester: John Wiley \& Sons.

Sekaran, U., \& Bougie, R. (2010). Research Methods for Business: A skill building approach (5th ed). Jakarta: Salemba Empat.

Siemsen, E., Roth, A.V., \& Balasubramanian, S. (2008). How motivation, opportunity, and ability drive knowledge sharing: The constraining-factor model. Journal of Operations Management, 26(3), 426-445.

Sugiyono. (2009). Metode Penelitian Bisnis. Bandung: Alfabeta.

Teh, Pai-Lee, \& Sun, H. (2012). Knowledge sharing, job attitudes and organisational citizenship behaviour. Industrial Management and Data Systems, 112(1), 64-82. 